\title{
New ELF Observation Site in Moshiri, Hokkaido Japan and the Results of Preliminary Data Analysis
}

\author{
Y. Hobara', N. Iwasaki², T. Hayashida², N. Tsuchiya², E. R. Williams" \\ M. Sera ${ }^{4}$, Y. Ikegami ${ }^{1}$ and M. Hayakawa ${ }^{2}$ \\ 1)Earth Observation Research Center, National Space Development Agency of Japan, 1-9-9 Roppongi, \\ Minato-ward, Tokyo 106-0032, Japan \\ ${ }^{2)}$ Department of Electronic Engineering, The University of Electro-Communications, Chofu, Tokyo \\ 182-8585,Japan \\ 3)Department of Earth, Atmospheric and Planetary Sciences, Massachusetts Institute of Technology, \\ Cambridge, MA 02139 U.S.A.
}

1) STE Lab. Moshiri Observatory, Nagoya University, Moshiri, Horokanai-cho, Hokkaido 074-0741, Japan

\begin{abstract}
Fully calibrated wide-band $(1 \mathrm{~Hz}<\mathrm{f}<1 \mathrm{kHz})$ three-component ELF measurement system has been installed as a permanent station in Moshiri, Hokkaido Japan in December 1996. We have been observing continuous background signals including Schumann resonances and ELF transient events. Preliminary data analysis shows the clear diurnal and seasonal patterns of global thunderstorm activities deduced from Schumann resonance amplitudes, and the global mapping of lightning locations are produced by using ELF events. Further the ELF events in association with mesospheric optical events are discussed.
\end{abstract}

Key words: Schumann resonances, ELF transients, global thunderstorm activity

\section{Introduction}

Recent findings of the mesospheric optical event; so-called sprite [Sentman et al., 1995] and elve [Fukunishi et al., 1996] showed a new light on the ELF (Extremely Low Frequency $3 \mathrm{~Hz}$ to $3 \mathrm{kHz}$ ) band, particularly the lower ELF range (Schumann resonance band) due to the strong correlation between ELF transient events and these optical phenomena [Boccippio et al., 1995]. Whereas, Williams [1992] proposed an idea that the global temperature change can be associated with the background Schumann resonance amplitude change due to an increase of global thunderstorm activities, which is the topic that our primary motivation of this study is placed on in collaborating with the MIT group. Furthermore, there is no permanent ELF observation site particularly using multicomponents in Japan since sometime ago (1960s)[Ogawa et al., 1967; 1969]. Based upon the above-mentioned stories, we established the permanent ELF site with wide-band and three components in Moshiri, Hokkaido Japan for continuous measurement of stationary background signals and transient events.

In this paper, we first of all describe our observation system, calibration scheme and software. Then we demonstrate some data obtained so far. Furthermore, the results of preliminary data analysis are presented.

\section{Observation System}

Wide-band ELF observation system was installed originally in December 1996 for the coordinated ELF/VLF measurement campaign between Australia and Japan (Moshiri (MSR), Hokkaido). At that time only two horizontal components were operating. After that 


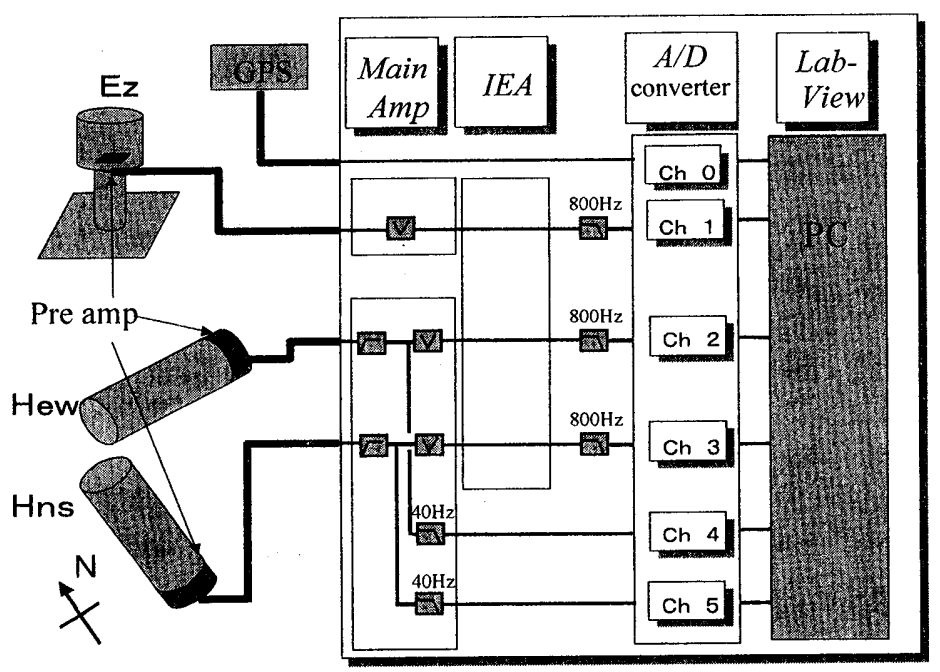

Fig. 1. The diagram illustrating our ELF observation system.

(a)

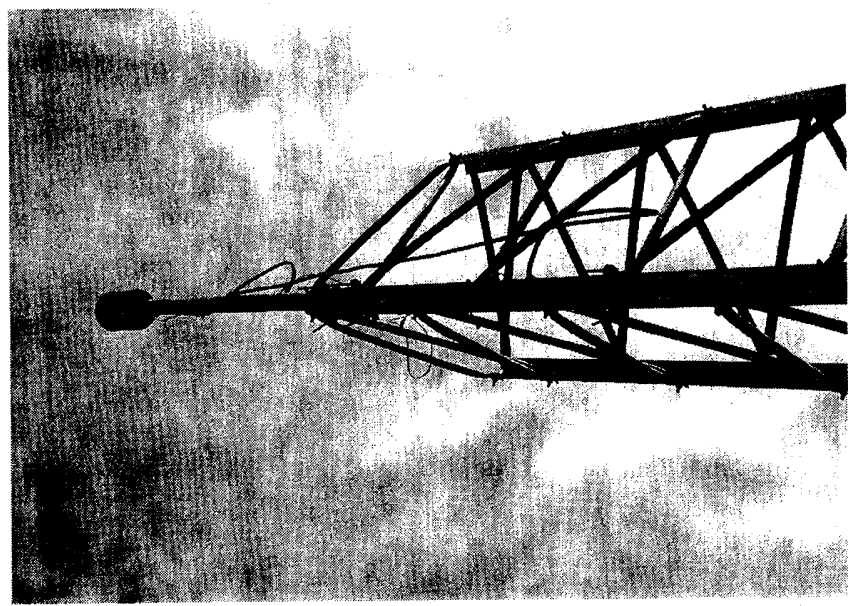

(b)

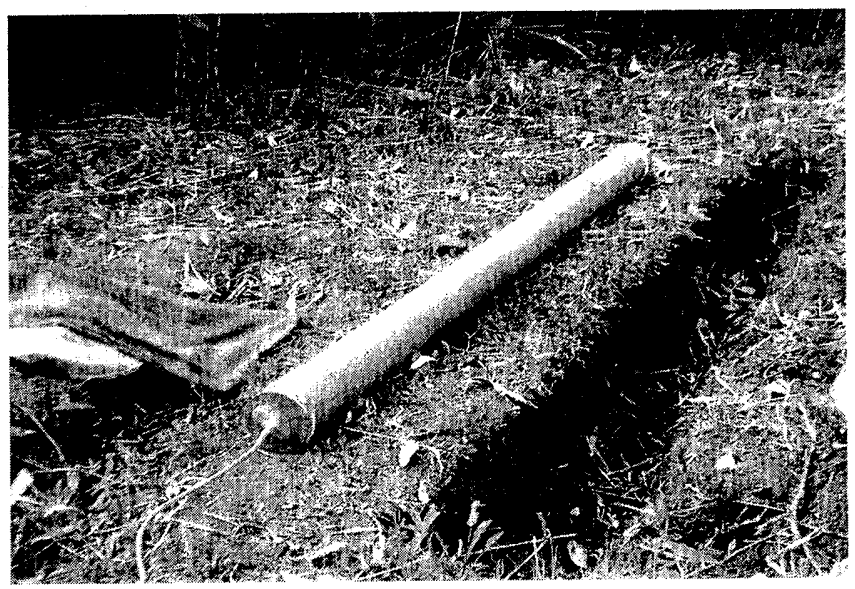

Figs. 2(a). Capacitor type antenna for vertical electric component (Ez), 2(b) induction type antenna for one of the horizontal magnetic field components (Hew). 
campaign we developed the system adding the vertical electric field component $(E z)$ as a permanent station in Asian region, and we revised the observation software suitable for the long term continuous measurement. Fig. 1 illustrates our three-component wide-band ELF/VLF measurement system. It consists of 3 orthogonal sensors (two horizontal magnetic field components and one vertical electric field component) with preamplifier, main amplifier and data acquisition system (A/D board with PC/AT computers with the observation software).

Vertical electric field is measured using a capacitor type antenna (cylindrical shape with its diameter of $15 \mathrm{~cm}$, height of $25 \mathrm{~cm}$ ) located at the top of the $10 \mathrm{~m}$-height tower shown in Fig. 2(a). This configuration of $E z$ component has been used since July 1997. Before that time the same type of antenna was used, but the antenna was set at the top of 5m-mast fixed by 4 wires and was rather unstable configuration especially when wind is strong. The preamplifier is housed within the antenna and whose transfer function with antenna equivalent capacitor assumed to be $10 \mathrm{pF}$ is deduced (Fig. 3(a)). As is seen in Fig. 3(a), the lower cutoff frequency is located at $4.25 \mathrm{~Hz}$. The average gain in the most part of frequencies is about $5.8 \mathrm{~dB}$. After initial amplification the output signal was fed to the main amplifier. Fig. 3(b) shows the frequency response of the main amplifier for $E z$. The average gain $G m$ is about $16.3 \mathrm{~dB}$ with an anti-aliasing filter with cut-off frequency set at $f=870 \mathrm{~Hz}$. Some set of band elimination filters are also installed at the center frequencies of 50,100 and $150 \mathrm{~Hz}$.

Two induction type magnetic sensors with permalloy cores $(160 \mathrm{~cm}-$ long and $7 \mathrm{~cm}$ in diameter) were buried orthogonally with geographical north-south (NS) and east-west (EW) directions. The low noise preamplifier is attached to the end of each induction coil and the frequency response for the magnetic field extends up to $1000 \mathrm{~Hz}$. Fig. 2(b) shows the photo of the one of the magnetic field components before setting. Each antenna is shielded by $13 \mathrm{~cm}$ diameter PVC pipe for water protection. Signals from the preamplifier pass through similar stages to the electric system employing notch-filters and anti-aliasing filters for each channel.

The electric and magnetic systems are calibrated carefully, because both amplitude and phase characteristics of the system are particularly important for correct determination of the polarity and the arrival direction of the event. Absolute calibration for $E z$ component is performed by comparing the output amplitude of capacitor type antenna used for field observation with calibration antenna (parallel-plate) consisting of two square metal plates of size $40 \mathrm{~cm}$ X $30 \mathrm{~cm}$ separated by $25.2 \mathrm{~mm}$ (known effective height) by receiving continuous VLF transmitter signal. Then we determined the effective height for the capacitor type antenna of $0.75 \mathrm{~m}$. Together with the frequency dependence of pre-amplifier and main amplifier shown in Figs. 3(a) and 3(b), we obtained the frequency dependence of the voltage conversion value (conversion from output voltage to the electric field $(\mathrm{V} / \mathrm{m})$ ) and phase response shown in Figs. 4(a) and 4(b) respectively. It appears that the absolute sensitivity of $E z$ is about $1.2 \mathrm{~V} / \mathrm{Vm}^{-1}$ for the most frequency range we use. $H$-field calibration is made by inserting each antenna to the $21.6 \mathrm{~cm}$ diameter and $200 \mathrm{~cm}$ long solenoidal winding on PVC pipe creating uniform magnetic field inside the pipe. By injecting the sinusoidal waves by the signal generator with different frequencies into these coils and comparing the final output of the receiving system with the input signal in the frequency domain using a spectrum analyzer, we derive the frequency response of voltage conversion value (amplitude and phase) for two magnetic components. Figs. 5(a) and 5(b) show the voltage conversion value and phase response of the magnetic system (east-west) component. The frequency responses of two components are nearly identical. The effect of the series of notch filters at frequencies of $50 \mathrm{~Hz}, 150 \mathrm{~Hz}$, IEA 
(Interference eliminating filter) and anti-aliasing filter located at the frequency of about $800 \mathrm{~Hz}$ (channels 2 and 3 ) are seen clearly. Another set of output has an upper frequency cutoff at $40 \mathrm{~Hz}$ focussing particularly the events in the Schumann Resonance band (channels 4 and 5).



(a)

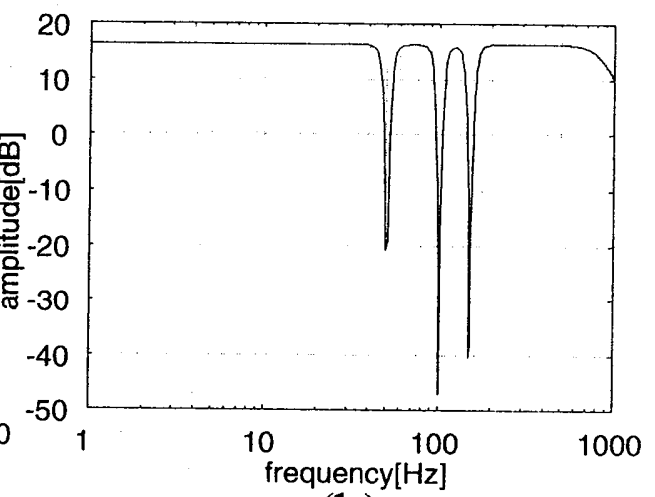

(b)

Figs. 3(a). The frequency response of the preamplifire for $E z$ component, 3(b) same variation for the main amplifier.

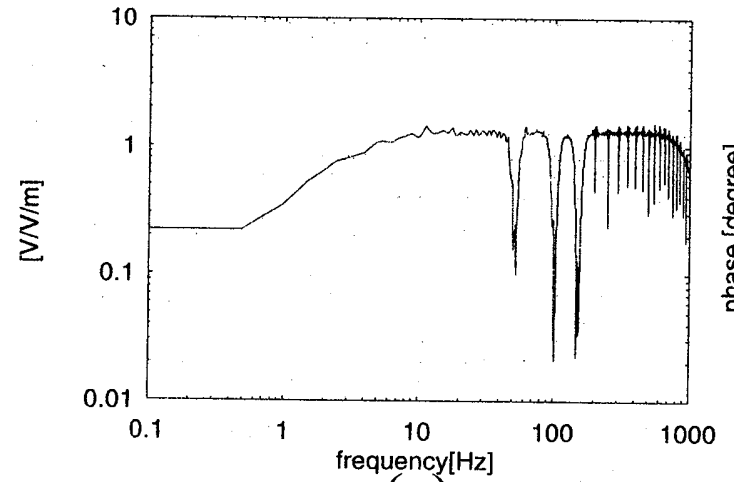

(a)

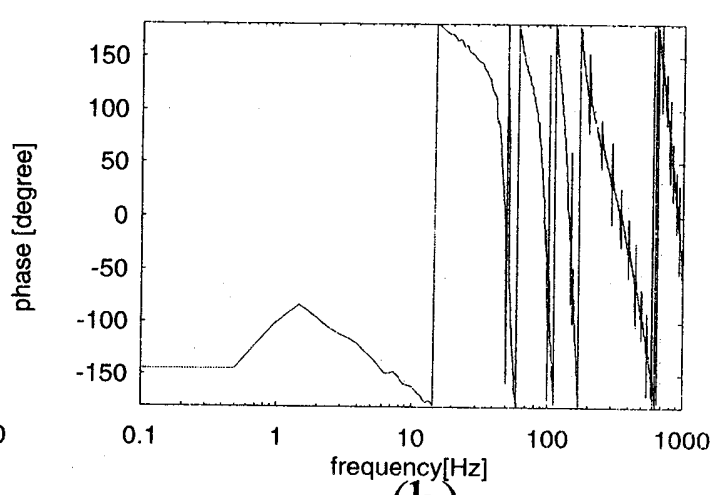

(b)

Figs. 4(a). The frequency variation of the voltage conversion value for whole $E z$ system, 4(b) the phase response for whole $E z$ system.



(a)



(b)

Figs. 5(a). The frequency variation of the voltage conversion value for whole Hns system, 5(b) the phase response for whole Hns system. 
Output from three components routed over shielded twisted pair cables to the main building where the main amplifiers and data acquisition systems are located through the distance about $150 \mathrm{~m}$ for $E Z$ and $200 \mathrm{~m}$ for $H$. Six analog signals (outputs from three sensors and 36 bit NASA code signal from GPS clock) are digitized at 2000 samples per second by two different DAQ boards (National Instruments AT-MIO-16E-10(16bit)) because we separate the data acquisition between background signals including Schumann resonances and ELF transients. For automatic data preprocessing and recording to the MO drive, we have developed the observation software using Lab View software (National Instruments) that controls the data acquisition timing, calculating the FFT spectra, creating the data files and showing the observation status on the screen. This program is working on Microsoft Windows 95 operating system. First of all, four channels (channels 2 to 5) of continuous background signals of $30 \mathrm{~s}(60000 \mathrm{pt})$ are sampled every minute and corresponding Fourier components are calculated. Furthermore, the frequency dependence of power spectral densities are viewed on the computer display for each minute and power spectral density (channels 4 and 5) and complex Fourier component (channels 2 and 3) averaged over each 10 minutes are saved periodically to 630 Mbytes magneto optical disc. Secondly, transient signals are pre-processed by using a different computer for background signal and captured only when the temporal total magnetic intensity is larger than the mean value calculated over each minute plus corresponding standard deviation. We extract the waveform of channels 0 to 3 (NASA code and 3 components with $800 \mathrm{~Hz}$ upper cutoff) and channel 5 (Hew with $40 \mathrm{~Hz}$ upper cutoff). Examples of the front panels of two different softwares (for background and transient) are shown in Figs. 6(a) and 6(b) respectively.

\section{Preliminary Results}

In this section we demonstrate some data and results from preliminary data analysis obtained by the above-mentioned system, which are from Schumann resonances and ELF transients.

\section{Schumann resonances}

Three different complex FFT spectra averaged over each ten minute from three field components (channels 1 to 3 ) are recorded. One example of frequency spectra is shown in Figs. 7(a) to 7(c). At least up to first five resonance modes are seen clearly in Ez and $H n S$ components, whereas first four resonance modes are seen in Hew. The peak intensity of each resonance varies with time. Figs. 8(a) to 8(c) and 9(a) to 9(c) show the temporal dependence of first three resonance amplitudes for five successive days for Hew and Hns components respectively. Amplitude is plotted in the unit of $\mathrm{pT} \mathrm{Hz}^{-1 / 2}$. The Hew component is sensitive to wave coming from north-south direction and first peak around 10 UT stands for Asia whereas another peak around 21 UT stems from South America coinciding with the local evening in each region. While only one enhancement of the intensity in $H n s$ is seen at about 14 UT everyday due to thunderstorm activity in Africa. Up to this point, it is found that three thunderstorm centers are separated clearly without any confusion by arrival direction and time dependence in Japanese site. The difference in the amplitude of enhancement between resonance modes is presumably due to the nodal effect. Furthermore intensity of resonances ranges from $0.3 \mathrm{pT} \mathrm{Hz}^{-1 / 2}$ to $0.6 \mathrm{pT} \mathrm{Hz}^{-1 / 2}$ and is good agreement with other experimental results [Sentman, 1995]. 


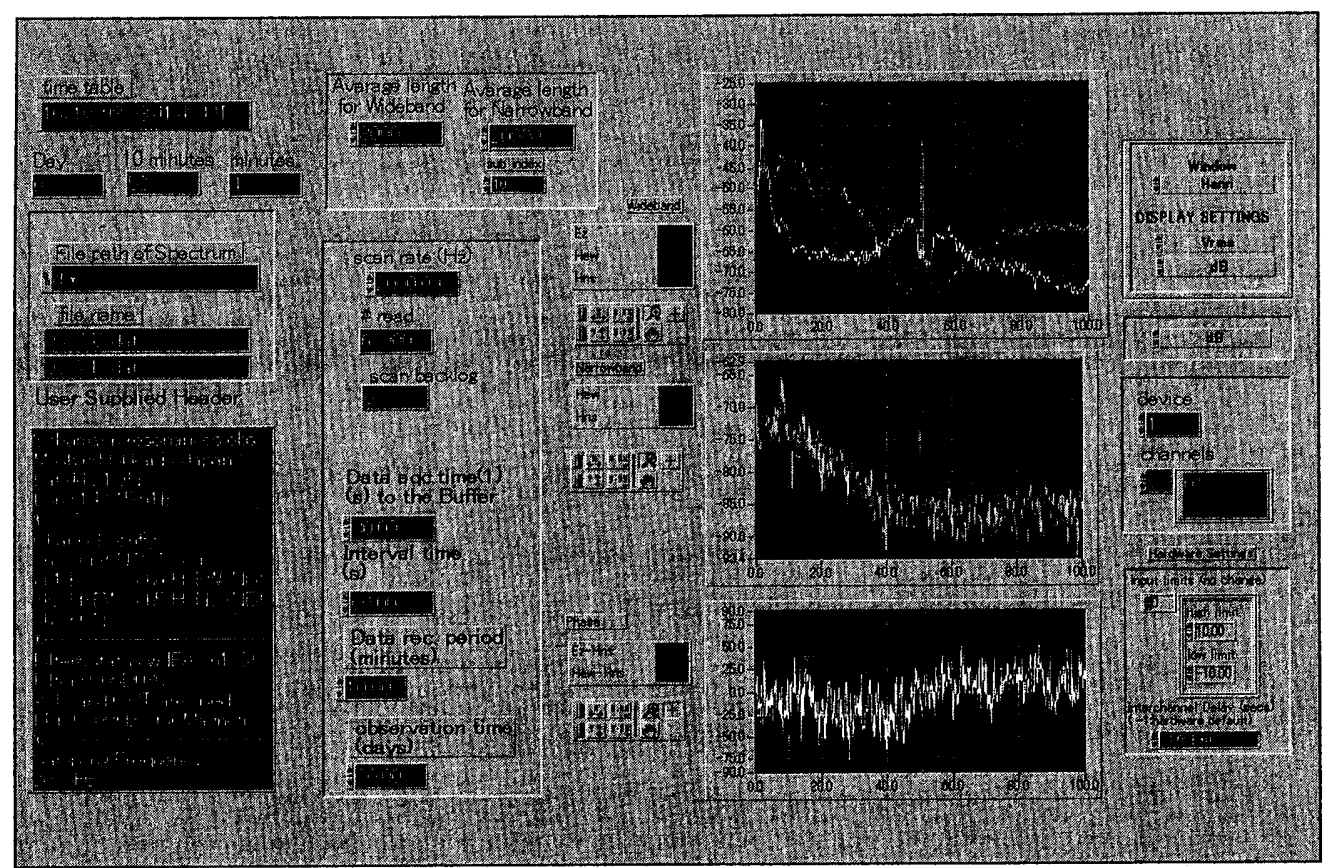

(a)

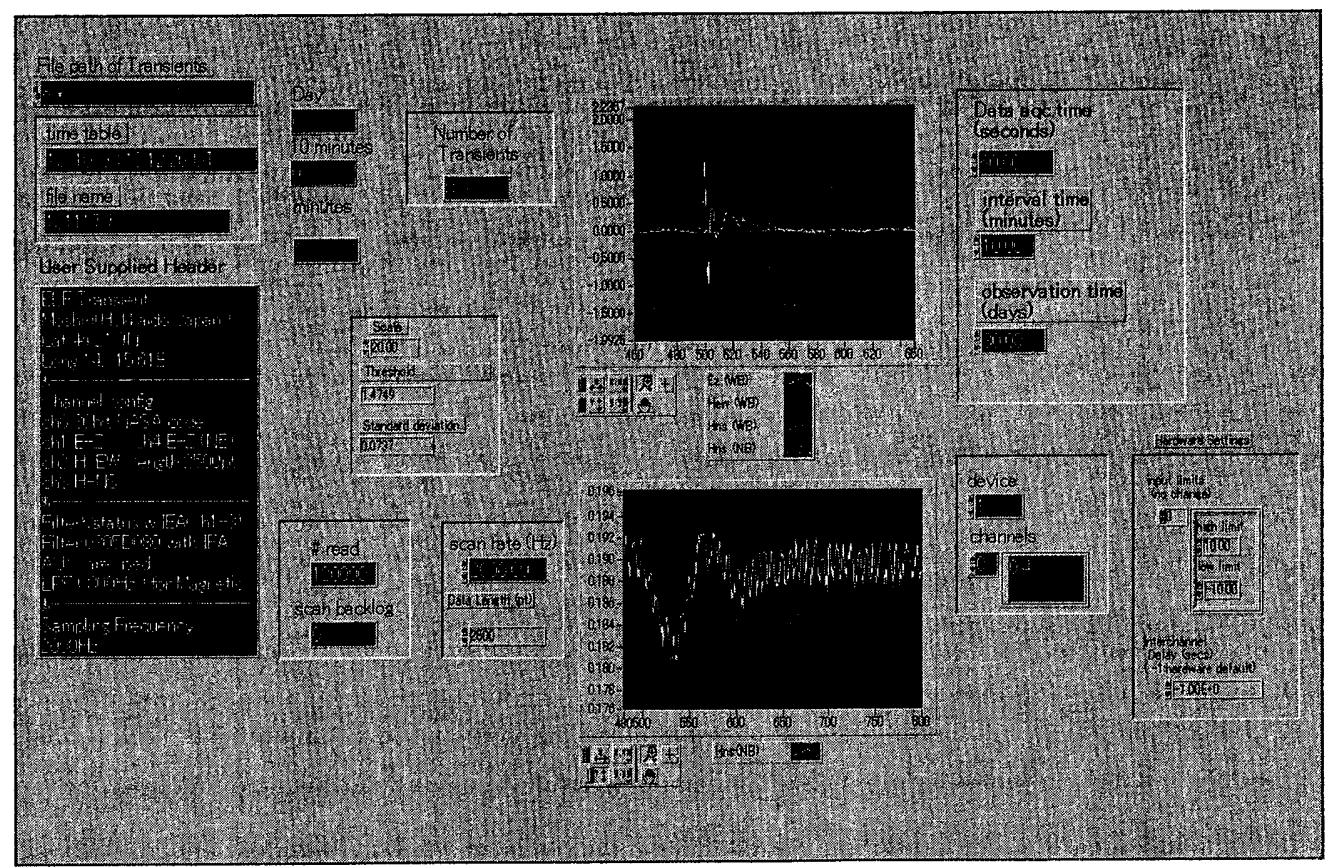

(b)

Figs. 6(a). Front panel of the observation software by Lab View appeared on the computer display for continuous observation of background, $6(\mathrm{~b})$ same variation for ELF transients. 



Figs. 7(a). An example of frequency spectrum of Schumann resonance band for $E z$ component, 7(b) same variation for Hew component, 7(c) same variation for Hns component.

\section{(a) $8 \mathrm{~Hz} \quad$ April 19, 1999}

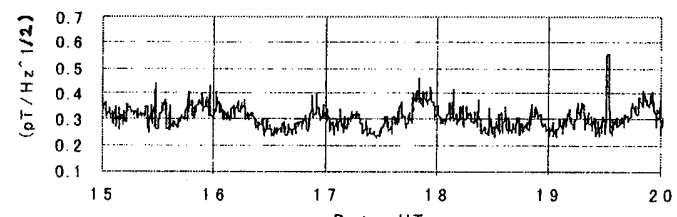

(b) $14 \mathrm{~Hz}$

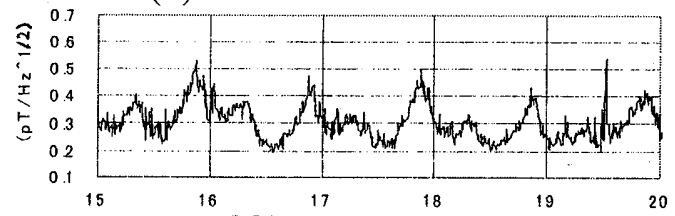

(c) $20 \mathrm{~Hz}$ Date (UT)



Figs. 8(a) to (c). Temporal dependence of amplitude of first three resonance modes for Hew. (a) $8 \mathrm{~Hz}$ April 19, 1999

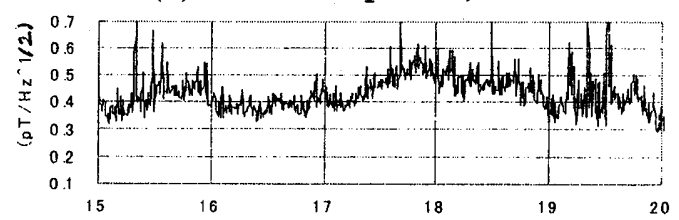

(b) $14 \mathrm{~Hz}^{\text {Date (Ur) }}$

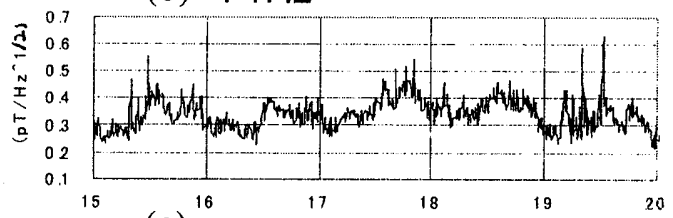

(c) $\left.{ }^{16} 2 \mathrm{HHz}^{17} \mathrm{zate}^{10}\right)^{18}$

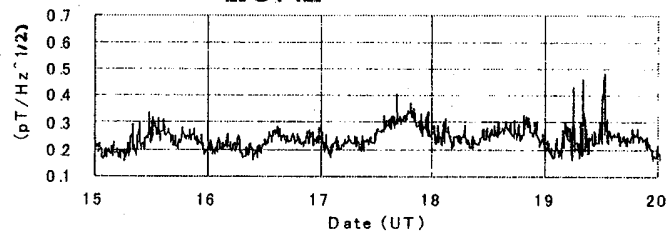

Figs. 9(a) to (c). Temporal dependence of amplitude of first three resonance modes for Hns. 
Based on the resonance intensities, we performed rather simple data analysis to derive the global and regional thunderstorm activities. Source intensity at particular time is calculated by summing up the power of first three resonance modes (larger number the better). This summing operation is considered to decrease the nodal effect or source-observer distance (SOD) effect [Nickolaenko et al., 1996]. According to their estimation, valid range of SOD which we can neglect the nodal effect is ranging from $4 \mathrm{Mm}$ to $14 \mathrm{Mm}$. The bar graph of the top panel of Fig. 10 shows the monthly variation of the global thunderstorm activities deduced from Schumann resonance amplitude. During the course of calculation, we take these different times corresponding to the amplitude peak from 3 thunderstorm active regions clearly distinguished from time and baring. As is seen in Fig. 10, clear annual variation with maximal value in the summer of northern hemisphere is apparent. However, there is no indication of winter lightning activity over Japan sea, which was seen in the results of similar type of analysis applied to the record in Tottori in 1960s [Nickolaenko et al., 1996]. It might be due to rather long distance from winter thunderstorm region to MSR comparing with one for Tottori. Besides, the positive trend in amplitude with time may indicate the difference of global thunderstorm activity in the different year. Bottom panel of Fig. 10 demonstrates the monthly variation of each thunderstorm center (Asia, Africa and South America). An Asian source is strongest in most time in the data period but the American source is strongest during August through October. Also a great increase of activity in Asia (25\%) and America (12\%) in May 1999 in comparison with the same period in the previous year. In any case, the above-mentioned data should be treated more carefully to exclude the local interference and the model accuracy. The data of longer time period can tell us more about these.

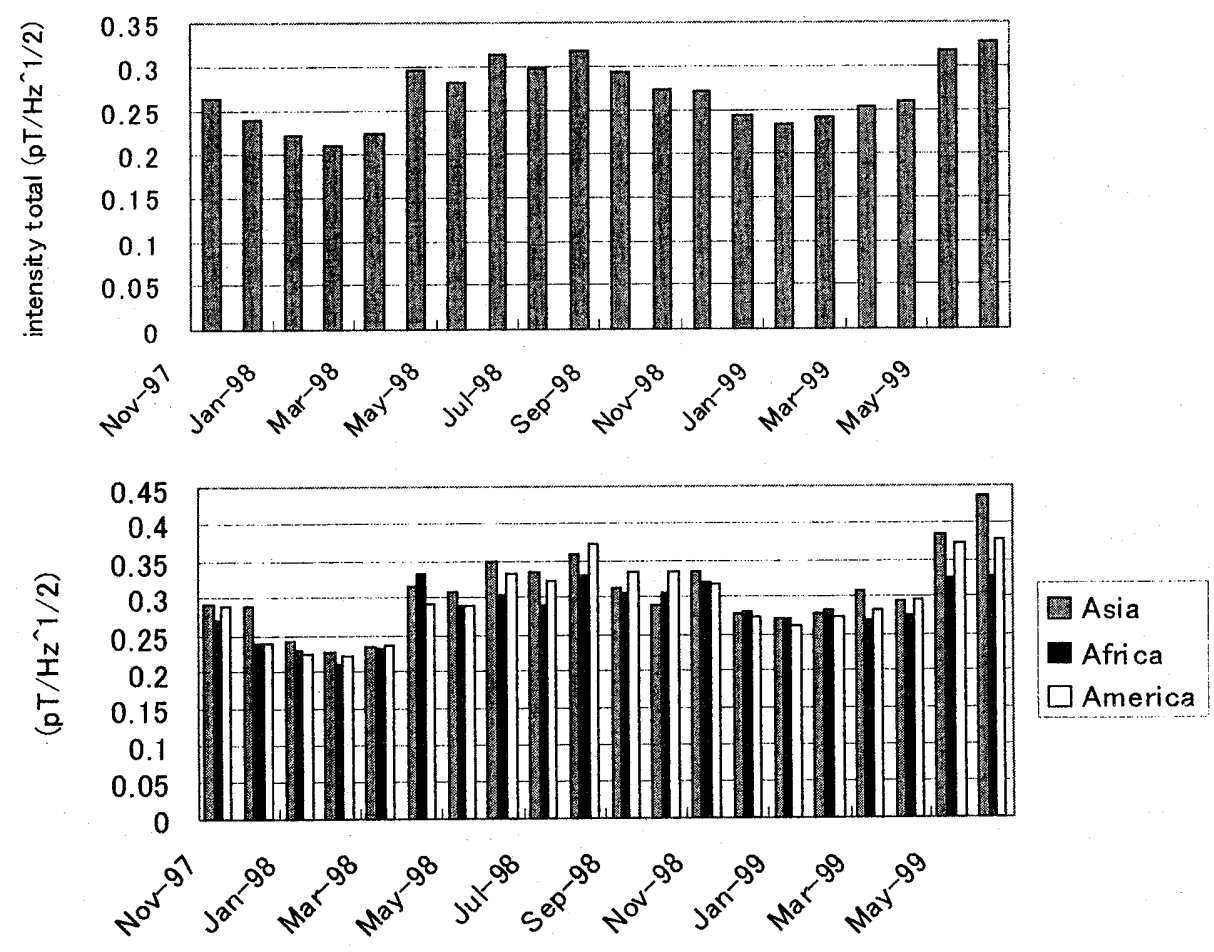

Fig. 10. Monthly variation of global thunderstorm activities (Top panel) and that of three different thunderstorm centers (Asia, Africa and America). 


\section{ELF Transients}

In this subsection, we move on to the ELF transient events, which are triggered by total magnetic field intensity. Thousands of events are recorded everyday. Our system can receive the transient electromagnetic events in association with remote thunderstorm centers all over the world in addition to the local ones outstanding in summer and winter time (winter lightning activity over Japan sea). Usual procedure applied to each event is, (1) waveforms of three field components are fourier transformed and the correction based on the system response is made, which produce calibrated frequency spectra and calibrated waveforms after inverse FFT, (2)Arrival angle is computed in the frequency domain by using simple goniometer technique which has a good accuracy only in the case of linearly polarized wave. Besides, we average the barings from the selected frequency components whose phase difference between $H n s$ and $H e w$ is smaller than 50 deg regarded as mostly linearly polarized wave. (3) The polarity of the event is determined by the sign of first excursion of the calibrated $E z$ waveform (a negative sign for the positive polarity and a positive sign for the negative polarity), (4) the wave impedance is calculated and we estimate the source observer distance, (5) the frequency dependence of the current moment $I(f) d s$ assuming the vertical electric dipole source with the height of $d s$ and charge transfer can be calculated as well.



Fig. 11. An example of the waveform of ELF event in association with sprite detected at 17:38:52:901 (UT) on December 19, 1998.

Fig. 11 shows an example of the waveform of ELF event observed during the winter lightning activity over Japan sea at 17:38:52.901 (UT) on December 19, 1998. This event coincides with the onset time of mesospheric optical event (sprite) observed by II CCD camera [H. Fukunishi, private communication] with rather small peak current Ip 39kA detected by JLDN (Japan Lightning Detection Network) which measures VLF wave field [Matsui et al., 1998]. While it exhibits the large current moment change $(f<50 \mathrm{~Hz})$ and estimated charge transfer of Q 60.1 C assuming the lightning channel length $d s$ as $5 \mathrm{~km}$ (typical altitude of the cloud top of the winter thunderstorm cloud) based on the impulsive estimation. Furthermore, sub-ionospheric condition monitored by a reception of VLF transmitter signals shows socalled RORD (Rapid Onset Rapid Decay) type nature [Dowden et al., 1996] suggesting a strong perturbation of the lower ionosphere in association with the above-mentioned particular ELF event. We detected ELF events in association with other optical event, elve, 
which appeared to have a smaller current moment change, charge transfer and ionospheric perturbation in comparison with those for sprites in spite of larger JLDN peak current. For both cases, polarity estimation from ELF events are positive coinciding with ones from JLDN.

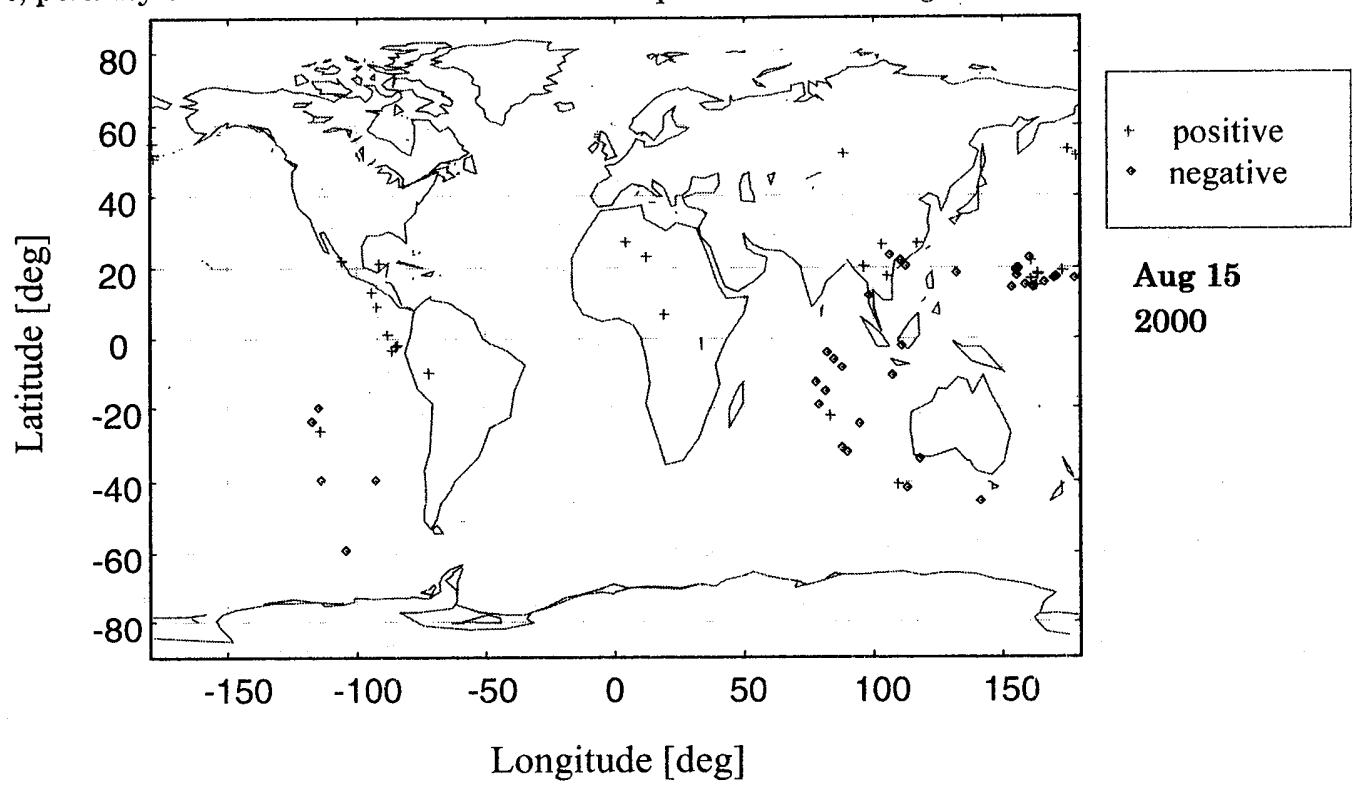

Fig. 12. An example of the global mapping of lightning sources derived from ELF events using the wave impedance method.

Another application of the ELF events is to locate the distant lightning events by single station. Fig. 12 illustrates the global mapping of the ELF sources based on the selected ELF events in MSR on Aug. 15 in 1999. The location estimated are in accord with what is known as global thunderstorm centers. Similar works have been done by several people [Burke and Jones, 1995; Huang et al., 1999] but our geographical site location is important particularly to complement the detection area, because the wave impedance method widely used in other stations can be applied for the SOD larger than $2 \mathrm{Mm}$ for the practical use. Nowadays at least several permanent ELF stations with three components operating all over the world, U.S., Hungary, Israel etc. Furthermore we will deduce the seasonal and yearly variation of source distribution.

\section{Summary and Conclusion}

Three-component wide-band: $(1 \mathrm{~Hz}<\mathrm{f}<1 \mathrm{kHz})$ ELF electro-magnetic measurement system was installed in Moshiri, Hokkaido Japan as only permanent station in Asia region now.

1. Our system observes successfully both background signals including Schumann resonances and ELF transient events from local and distant sources.

2. Full calibration of the system has been made carefully, which is necessary to determine the quantitative characteristics of the sources and the wave arrival direction.

3. According to the preliminary data analysis;

(a)Diurnal and seasonal variations of global thunderstorm activities are deduced for about one year period.

(b)An example of ELF events in association with mesospheric optical events (sprites) 
is shown and it is used to estimate the current moment and charge transfer for the causative lightning.

(c) We produced the global map of lightning from intensive distant sources for entire globe by single observation site (MSR) using the wave impedance method, which would be useful to monitor the spatio-temporal evolution of global thunderstorm activities economically.

\section{References}

Boccippio, D. J., E. R. Williams, S. J. Heckman, W. A. Lyons, I. T. Baker, and R. Boldi, ELF transients and positive ground strokes, Science, 269, 1088-1091, 1995.

Burke, C. P. and D. Ll. Jones, Global radiolocation in the Lower ELF frequency band, $J$. Geophys. Res., 100, (D12), 26,263-26,272, 1995.

Dowden, R. L., J. B. Brundell, and W. A. Lyons, Are VLF rapid onset, rapid decay perturbations produced by scattering off sprite plasma?, J. Geophys. Res., 101, 19,175-19,184, 1996.

Fukunishi, H., Y. Takahashi, M. Kubota, K. Sakanoi, U. S. Inan, and W. A. Lyons, Elves: Lightning-induced transient luminous events in the lower ionosphere, Geophys. Res. Lett., 23, 2157-2160, 1996.

Huang E., E. Williams, R. Boldi, S. Heckman, W. Lyons, M. Taylor, T. Nelson, and C. Wong, Criteria for sprites and elves based on Schumann resonance observations, J. Geophys. Res., 104, 16,943-16,964, 1999.

Matsui, M., Y. Miyake, S. Takahashi, The Introduction of the Japan Lightning Detection Network, International Lightning Detection Conference, 1998.

Nickolaenko A. P., M. Hayakawa, and Y. Hobara, Temporal variations of the global lightning activity deduced from the Schumann resonance data, J. Atmos. Terr. Phys., 58, 1699-1709, 1996.

Sentman, D. D., Schumann Resonances, in H. Volland (ed.), Handbook of Atmospheric Electrodynamics, Boca Raton, CRC Press, 267-310, 1995.

Sentman, D. D., E. M. Wescott, D. L. Osborne, D. L. Hampton and M. J. Heavner, Preliminary Results from the Sprites 94 Aircraft Campaign: 1. Red Sprites, Geophys Res. Lett., 22, 12051208, 1995.

Ogawa, T., Y. Tanaka and M. Yasuhara, A. C. Fraser-Smith and R. Gendrin, Worldwide simultaneity of occurrence of a Q-type ELF burst in the Schumann resonance frequency range, J. Geomag. Geoelectr., 19, 377-385, 1967.

Wiliams, E. R., The Schumann resonance: a global tropical thermometer, Science, 256, 1184, 1992.

Ogawa, T., Y. Tanaka and M. Yasuhara, Schumann resonance and worldwide thunderstorm activity-Diurnal variation of the resonant power of natural noises in the Earth-ionosphere cavity, J. Geomag. Geoelectr., 21, 447-452, 1969.

(Received June 19, 2000; revised July 12, 2000; accepted August 9, 2000) 